\title{
Democracia, Radicalización, y Agencia Política en América Latina
}

\author{
Democracy, Radicalization, and Political Agency in Latin America
}

\section{Aníbal Pérez-Liñán}

\section{Resumen}

Este trabajo integra los resultados empíricos de cuatro estudios cuantitativos para analizar las consecuencias de la radicalización política para las democracias latinoamericanas. La primera sección define la idea de radicalización y su operacionalización. Las secciones siguientes exploran las consecuencias de la radicalización del gobierno y de la oposición para la supervivencia de los gobiernos electos y del régimen democrático; la capacidad de los gobiernos radicalizados para debilitar la competencia política en períodos de rápido crecimiento económico; y las consecuencias de la erosión institucional y la polarización para la inestabilidad del régimen. Esta evidencia nos obliga a replantear la responsabilidad de los líderes políticos y su capacidad de agencia como paso fundamental para pensar el futuro de la región.

\section{Palabras clave}

Democracia; Radicalización; Inestabilidad Política; América Latina.

\begin{abstract}
This article integrates the empirical findings of four quantitative studies to analyze the consequences of political radicalization to Latin American democracies. The first section of the paper defines and operationalizes the concept of radicalism. The following sections explore the consequences of radicalization among the government and the opposition for the survival of elected governments and of the democratic regime; the capacity of radical governments to undermine political competition in periods of fast economic growth, and the consequences of institutional erosion and polarization for regime instability. The evidence presented in the paper calls for reassessing the role of political leadership and its agency to understand the future of the region.
\end{abstract}

\section{Keywords}

Democracy; Radicalization; Political Instability; Latin America. 


\section{Introducción ${ }^{1}$}

¿Qué factores determinarán el futuro de las democracias latinoamericanas? ¿Y cuál es la responsabilidad de los actores políticos en la construcción de este futuro? El presente trabajo aborda estas dos cuestiones enfatizando la importancia del liderazgo político, y su capacidad de agencia, como premisas fundamentales para el análisis de los procesos de democratización.

La pregunta sobre el futuro de la democracia resulta particularmente urgente. Desde mediados de los ańos noventa la democracia latinoamericana parece libre de la amenaza militar que dominó buena parte de la vida política durante el siglo pasado. Pero los regímenes de la región muestran actualmente trayectorias muy distintas. Aunque enfrentan serios desafíos, países como Brasil y México han experimentado un importante desarrollo democrático cuando comparamos su situación actual con la de dos décadas atrás. Otros países, por el contrario, han experimentado procesos de estancamiento o erosión democrática y confrontan una incertidumbre mayor. Cuando en Ecuador y Venezuela los movimientos ciudadanos desafían al gobierno, es el régimen mismo - apenas diferenciable del liderazgo en el poder - el que se ve cuestionado.

Estos cuestionamientos se producen, paradójicamente, después de una década de notable crecimiento económico. Entre 2000 y 2008 el valor total de las exportaciones aumentó anualmente un 21 por ciento en Perú, un 17 por ciento en Brasil y Chile, y un 13 por ciento en Argentina (ROS, 2013). Gran parte de este crecimiento fue impulsado por la expansión de la economía china que amplió la demanda mundial de minerales, energía y alimentos. Entre 2006 y 2011, las exportaciones de América del Sur a China crecieron tres veces más rápido que las exportaciones al resto del mundo (URCUYO, 2013).

La expansión de los mercados asiáticos incrementó abruptamente la demanda mundial de productos primarios: soja de Argentina, Paraguay y Uruguay; gas y minerales de Bolivia; petróleo de Ecuador y Venezuela; cobre de Chile. Desafiando los principios clásicos de la teoría de la dependencia, los términos de intercambio se apreciaron en favor de las exportaciones primarias durante la primera década del siglo (MAZZUCA, 2013; ROS, 2013). Los beneficios de la globalización fueron menos claros para América Central, en donde la industria maquiladora tuvo que competir

\footnotetext{
${ }^{1}$ Una versión previa de este trabajo fue presentada en el seminario internacional "Los dilemas de la democracia en América Latina: a cuatro décadas de la transición”. FLACSO México e Instituto de Investigaciones Jurídicas, UNAM. Ciudad de México, 30 de septiembre al 2 de octubre de 2015. Agradezco los comentarios de Gabriela Cantú Ramos.
} 
con las manufacturas chinas, y en donde las condiciones sociales, incluyendo el crimen organizado y la violencia urbana, se deterioraron. Pero Panamá prosperó bajo el auge del comercio global, y los gobiernos de Cuba y Nicaragua se beneficiaron de la generosidad venezolana, traducida en préstamos y combustible subvencionado para sus aliados regionales.

El efecto de esta prosperidad para el desarrollo democrático fue sin embargo notablemente desigual. En algunos países, la expansión económica estuvo acompañada de una política diversa y plural, mientras que en otros condujo a una polarización del debate público y a una reducción de la competencia política. ¿Cómo explicar estas trayectorias divergentes en un contexto global de prosperidad?

El argumento esbozado en este trabajo puede resumirse de la siguiente manera: los líderes políticos con preferencias radicalizadas - un término explicado en la sección siguiente - desarrollan como objetivo primordial el control hegemónico de las instituciones políticas. Y en la medida en que estos objetivos hegemónicos se ponen de manifiesto, la supervivencia de los gobiernos electos y la estabilidad del régimen democrático se ven amenazadas. Una oposición radicalizada busca desestabilizar al gobierno por cualquier medio disponible, sea éste institucional o para-institucional, mientras que un gobierno radicalizado busca restringir el debate público y reducir los niveles de competencia política. Los gobiernos interesados en restringir la deliberación pública se ven favorecidos por los ciclos de rápido crecimiento económico, porque estos períodos permiten aumentar el gasto social, fortalecer su capacidad de movilización, ganar influencia sobre las instituciones de control y los medios de comunicación, y finalmente debilitar la competencia política. Sin embargo, la experiencia de América Latina en las últimas siete décadas muestra que estas formas de erosión institucional producen una dinámica de polarización y conflicto político que lleva fácilmente a la quiebra del régimen democrático.

Para respaldar este argumento, las páginas siguientes reconstruyen un mosaico de evidencia empírica a partir de varios trabajos de investigación desarrollados en años recientes. Todos estos proyectos tienen un origen común en la investigación histórica sobre radicalización de los actores políticos latinoamericanos producida como parte de los estudios sobre democracias y dictaduras en América Latina. En la primera sección describo la idea de radicalización, su operacionalización, y sus consecuencias para la polarización de la vida democrática. Las secciones siguientes exploran las consecuencias de la radicalización del gobierno y de la oposición para la supervivencia de los gobiernos electos y del régimen democrático; la capacidad de los gobiernos radicalizados para debilitar la competencia política en períodos de rápido 
crecimiento económico; y las consecuencias de la erosión institucional y la polarización para la inestabilidad del régimen democrático. Esta evidencia nos obliga a replantear la responsabilidad de los líderes políticos y su capacidad de agencia como paso fundamental para pensar el futuro de la democracia en la región.

\section{Radicalización e intolerancia}

Los actores políticos no responden mecánicamente a las condiciones estructurales de su ambiente. Líderes y organizaciones forman sus preferencias por ciertas políticas públicas en un contexto histórico dado, y estos principios orientan su postura con respecto al gobierno y al régimen político. Sus preferencias se ven influidas - pero no determinadas - por condiciones estructurales $y$, aunque no son inmutables, una vez formuladas estas preferencias tienden a ser relativamente estables en el mediano plazo.

Las preferencias sustantivas de los actores varían en función de diferentes dimensiones - por ejemplo, éstas pueden ubicarse en diferentes posiciones a lo largo de un continuo izquierda-derecha - pero el atributo de mayor relevancia para la vida democrática es el grado de radicalismo (o moderación) de estas preferencias.

Los actores son radicales cuando sus objetivos de política pública están ubicados en los polos del espectro político, y cuando además expresan impaciencia para alcanzar estos objetivos (si no representan el status quo) o intransigencia para protegerlos (si ya constituyen el statu quo). Si bien las preferencias radicales no siempre son necesariamente de extrema izquierda o de extrema derecha, la distancia entre éstas y las preferencias de otras fuerzas relevantes es suficiente como para generar polarización cuando los actores radicalizados buscan imponer sus objetivos a cualquier costo. Se trata de preferencias intensas: las fuerzas radicales no están dispuestas a negociar o a esperar el largo plazo para instaurar sus políticas.

La presencia de actores radicales poderosos dificulta la supervivencia de los regímenes competitivos, ya sea que el radicalismo se origine en el gobierno o en la oposición. Cuando el gobierno tiene una agenda política radical, los actores de oposición temen que el éste utilizará el poder del estado para imponerles costos irreversibles, lo que reduce su disposición a tolerar el régimen existente. Por otra parte, el surgimiento de una oposición radicalizada a menudo constituye una amenaza para el gobierno y para otros actores arraigados en el sistema político, y estas fuerzas poderosas pueden subvertir el régimen competitivo para proteger sus intereses y reprimir la radicalización (DAHL, 1971; MAINWARING y PÉREZ-LIÑÁN, 2013). 
La competencia política en un contexto de radicalización genera así incertidumbre sobre el futuro y temor a que las fuerzas intransigentes impongan costos extremos al resto de la sociedad. Bajo esta dinámica polarizante, la probabilidad de que el régimen sobreviva disminuye (BERMEO, 2003; LEVINE, 1973; LINZ, 1978). En cambio, cuando las fuerzas políticas tienen preferencias moderadas, los actores poderosos en el gobierno y la oposición consideran improbable que un régimen competitivo les imponga pérdidas permanentes, y esto aumenta la disposición de estos actores para aceptar la competencia democrática (KARL, 1987).

Uno de los principales desafíos para evaluar esta hipótesis radica en cómo medir el nivel de radicalización entre los actores políticos. Para abordar este problema, conformamos un equipo de diecinueve asistentes de investigación, quienes recibieron reglas de codificación detalladas y elaboraron extensos informes sobre 20 países latinoamericanos. El equipo identificó libros y artículos que hacían referencia a la historia política de cada país, y empleó estas fuentes para describir los principales actores políticos en el período histórico correspondiente a cada gobierno entre 1944 y 2010. Los informes identificaron un conjunto limitado de actores - generalmente entre 3 y 7 - que aparecían de forma prominente en la historiografía de cada período de gobierno. La lista incluye líderes, organizaciones y movimientos con suficientes recursos para definir la competencia por el poder ${ }^{2}$. En conjunto, el proyecto identificó un total de 1.460 actores políticos en 290 períodos de gobierno. Estos actores fueron clasificados como parte del gobierno (o sus aliados) o como parte de la oposición (MAINWARING y PÉREZ-LIÑÁN, 2013).

Los investigadores codificaron a los actores políticos como radicales cuando satisfacían alguna de las siguientes condiciones: (1) el actor expresaba una preferencia inflexible por las políticas de izquierda o de derecha en el corto plazo, o por preservar estas políticas extremas cuando ya hubieran sido adoptadas; o (2) expresaba su deseo de subvertir el orden legal para alcanzar sus objetivos de política pública. El gobierno también fue codificado como radical cuando (3) implementó políticas que polarizaron a la sociedad y que impusieron costos significativos a otros actores de manera deliberada (por ejemplo, las expropiaciones sin compensación, o las normas laborales represivas para aumentar la oferta laboral). Los actores no gubernamentales

\footnotetext{
${ }^{2}$ Además del presidente, casi siempre identificado como un actor poderoso la lista también incluye partidos políticos, fuerzas armadas, asociaciones empresariales, grupos guerrilleros, organizaciones populares y sindicatos obreros.
} 
fueron codificados como radicales cuando (4) emprendían acciones violentas destinadas a imponer (o impedir) un cambio significativo en las políticas públicas. Cuando los actores se encontraban internamente divididos o tuvieron una actitud ambigua en torno a estas cuestiones, fueron codificados como "parcialmente" radicales. Cuando no se cumplía ninguna de las condiciones enunciadas, los actores fueron codificados como "moderados".

Figura 1 - Evolución de la radicalización en los regímenes competitivos



Fuente: Pérez-Liñán y Mainwaring, 2015a.

La Figura 1 muestra la evolución anual de esta variable para los regímenes competitivos (democracias o semi-democracias) en América Latina. Los países fueron considerados democráticos cuando presentan (1) elecciones libres y competitivas, (2) sufragio universal, (3) respeto pleno por las libertades civiles, y (4) supremacía de los gobernantes electos. Cuando alguna de estas cuatro condiciones institucionales se ve parcialmente erosionada, el régimen es considerado semi-democrático (MAINWARING, BRINKS y PÉREZ-LIÑÁN, 2007). Cuando alguna de estas condiciones está plenamente ausente, el régimen es considerado autoritario y el paísaño en cuestión no es incluido en este gráfico. Cada actor fue codificado con un valor de 1 (radical), 0,5 (parcialmente radical) o 0 (moderado). Las series muestran que las fuerzas radicales nunca fueron dominantes en las democracias de la región (aunque sí prevalecieron en algunos países en ciertos períodos). La radicalización de los 
gobiernos - excluyendo regímenes autoritarios - alcanzó sus mayores niveles en 1948 y en 1970, mientras que la radicalización de la oposición fue mayor hacia 1964 y 1980. Los niveles medios de radicalización han sido relativamente bajos a partir de los años noventa, aunque se observa un cierto crecimiento de la radicalización de las fuerzas gubernamentales a partir de 2002.

Aprovechando el acceso público a estos datos, hemos empleado los indicadores comparativos de radicalización para evaluar el impacto de esta variable en tres procesos políticos: (1) la estabilidad presidencial; (2) la competencia partidaria y (3) la erosión de la democracia ${ }^{3}$. Las secciones siguientes resumen los resultados principales de estos estudios. En lugar de reportar los detalles estadísticos de cada análisis (disponibles en los trabajos referidos) este artículo busca por primera vez integrar estos resultados en un argumento común.

\section{Consecuencias para la estabilidad presidencial}

Hasta la década de 1990, muchos presidentes latinoamericanos fueron derrocados por golpes militares. En los últimos ańos, en cambio, las renuncias anticipadas y las destituciones por medio del juicio político se han vuelto más comunes. En un trabajo realizado con John Polga-Hecimovich buscamos integrar la literatura sobre golpes militares y sobre presidencias interrumpidas para desarrollar una teoría unificada de la inestabilidad presidencial (PÉREZ-LIÑÁN y POLGAHECIMOVICH, 2015).

¿Por qué algunos presidentes son destituidos por medio de un golpe militar mientras que otros son removidos por un mecanismo civil como el juicio político o la presión popular? La respuesta a este interrogante tiene tres partes. En primer lugar, existen condiciones políticas que simplemente debilitan al presidente y pueden conducir a una destitución civil o militar. Por ejemplo, las manifestaciones populares generalmente desestabilizan al gobierno, pero son las élites políticas quienes en última instancia definen la estrategia para deponer al presidente. En segundo lugar, existen poderosos mecanismos de difusión regional que facilitan el uso de una u otra estrategia en diferentes momentos históricos. En la medida en que la región experimentó una ola de democratización a partir de los años ochenta y las normas internacionales condenaron más enérgicamente los golpes de estado, la salida militar se volvió mucho más costosa. Por lo tanto, las élites sustituyeron crecientemente la opción militar con mecanismos institucionales de destitución.

\footnotetext{
${ }^{3}$ La información sobre radicalismo se encuentra disponible en Pérez-Liñan y Mainwaring (2014).
} 
En tercer lugar, nuestro estudio muestra que el patrón de radicalización de los actores políticos tiene una influencia central en la resolución, civil o militar, de una crisis presidencial. Cuando los actores radicales se encuentran en la oposición, éstos emplean de manera oportunista cualquier estrategia disponible (constitucional o no) para derrocar al presidente. Las oposiciones radicalizadas niegan la legitimidad del gobierno para adoptar políticas que les resultan intolerables, y cuestionan el derecho del gobierno electo a perseguir su agenda cuando ésta ignora sus preferencias. Los opositores pueden ser radicalmente recalcitrantes - cuando buscan proteger el statu quo - o radicalmente transformadores - cuando buscan cambiarlo -. Por lo tanto, los presidentes electos pueden enfrentar desafíos desestabilizadores desde la derecha o desde la izquierda, cuando tratan de alterar las políticas existentes o cuando tratan de preservarlas. Para detener al gobierno, los opositores radicales pueden emplear un golpe militar, un juicio político en el congreso, o una movilización popular, dependiendo de las circunstancias.

Los gobiernos radicalizados también influencian las condiciones de su propia caída. Como buscan imponer sus políticas contra toda resistencia, estos gobiernos utilizan prerrogativas ejecutivas para evadir el control parlamentario, aprovechan sus mayorías legislativas para hacerse con el control de los tribunales, o convocan asambleas constituyentes para reorganizar el congreso tanto como los tribunales. Esta intrusión en la separación de poderes tiene varias consecuencias importantes. Debido a que las instituciones de rendición de cuentas se debilitan, los opositores moderados pierden los medios a su alcance para limitar el gobierno. En este contexto, los opositores radicales emergen como la voz dominante en contra de la administración. Linz (1978) describe este proceso como la "abdicación" de los moderados, pero en la mayoría de los casos moderados no abdican; sus estrategias se tornan ineficaces frente a la polarización de los otros líderes (BERMEO, 2003).

Los presidentes radicalizados se "blindan" así frente a los desafíos institucionales, pero canalizan la energía de las fuerzas opositoras hacia conspiraciones inconstitucionales. Dado que no resulta posible emplear medios legales para enjuiciar al presidente, una oposición cada vez más recalcitrante se inclina crecientemente hacia una alternativa militar. Por esta razón, los gobiernos radicales son más propensos a caer como consecuencia de un golpe militar que como resultado de un proceso constitucional.

Para comprobar este argumento utilizamos los datos sobre radicalización del gobierno y la oposición presentados anteriormente, y estimamos un modelo estadístico de riesgos competitivos en el que las unidades de análisis son los 
presidentes electos observados durante cada año de su mandato $(n=729$, para 19 países en el período 1945-2010). La variable dependiente en este modelo captura si el presidente (1) completa el año en el cargo, (2) es removido por medio de un golpe militar, o (3) es removido por medio de un mecanismo civil, como el juicio político, la declaración de incapacidad, o la renuncia involuntaria.

Entre las variables independientes que explican la inestabilidad presidencial en este modelo se encuentran los niveles de radicalismo del gobierno y de la oposición, el número de manifestaciones en contra del gobierno y de saqueos ocurridos durante el año, la cantidad de golpes militares o destituciones civiles ocurridas en otros países de la región en los últimos cinco años, la frecuencia de golpes o destituciones ocurridas en el mismo país durante los veinte años anteriores al año observado, la tasa de crecimiento económico y el nivel de ingreso per cápita ${ }^{4}$.

Los resultados de este análisis muestran que la presencia de una oposición radicalizada aumenta el riesgo de un golpe de estado tanto como el de una destitución civil. Por el contrario, la presencia de un gobierno radicalizado se correlaciona con un mayor riesgo de golpe militar, pero no de destitución por medios institucionales. Si bien el coeficiente no es estadísticamente significativo, el efecto del radicalismo gubernamental en la probabilidad de destitución civil tiende a ser negativo, lo que resulta consistente con la idea de que los gobiernos intransigentes bloquean los espacios institucionales que pueden presentarles un desafío.

La Figura 2 resume las predicciones de este modelo estadístico bajo seis diferentes escenarios. Todos los paneles muestran que el riesgo de destitución (por medios civiles o militares) se incrementa a medida que las protestas sociales se tornan más frecuentes, lo que indica que las élites opositoras se ven fortalecidas por la caída en la popularidad del gobierno (HOCHSTETLER, 2006). Las tres imágenes en la primera fila ilustran el riesgo estimado de una destitución civil mientras que las imágenes en la segunda fila reflejan el riesgo de un golpe militar. La primera columna corresponde a situaciones en donde tanto el gobierno como la oposición son moderados (es decir, tienen valores de 0 en la escala de radicalismo); la segunda columna simula una situación en la que sólo la oposición se ha radicalizado, y la tercera columna refleja un escenario en donde todos los actores están radicalizados.

\footnotetext{
4 Empleamos un estimador logístico multinomial con efectos aleatorios por país. Las salidas "normales" (por ejemplo, cuando un presidente termina el mandato) son consideradas como casos censurados.
} 
Figura 2 - Riesgo de destitución civil o de golpe militar
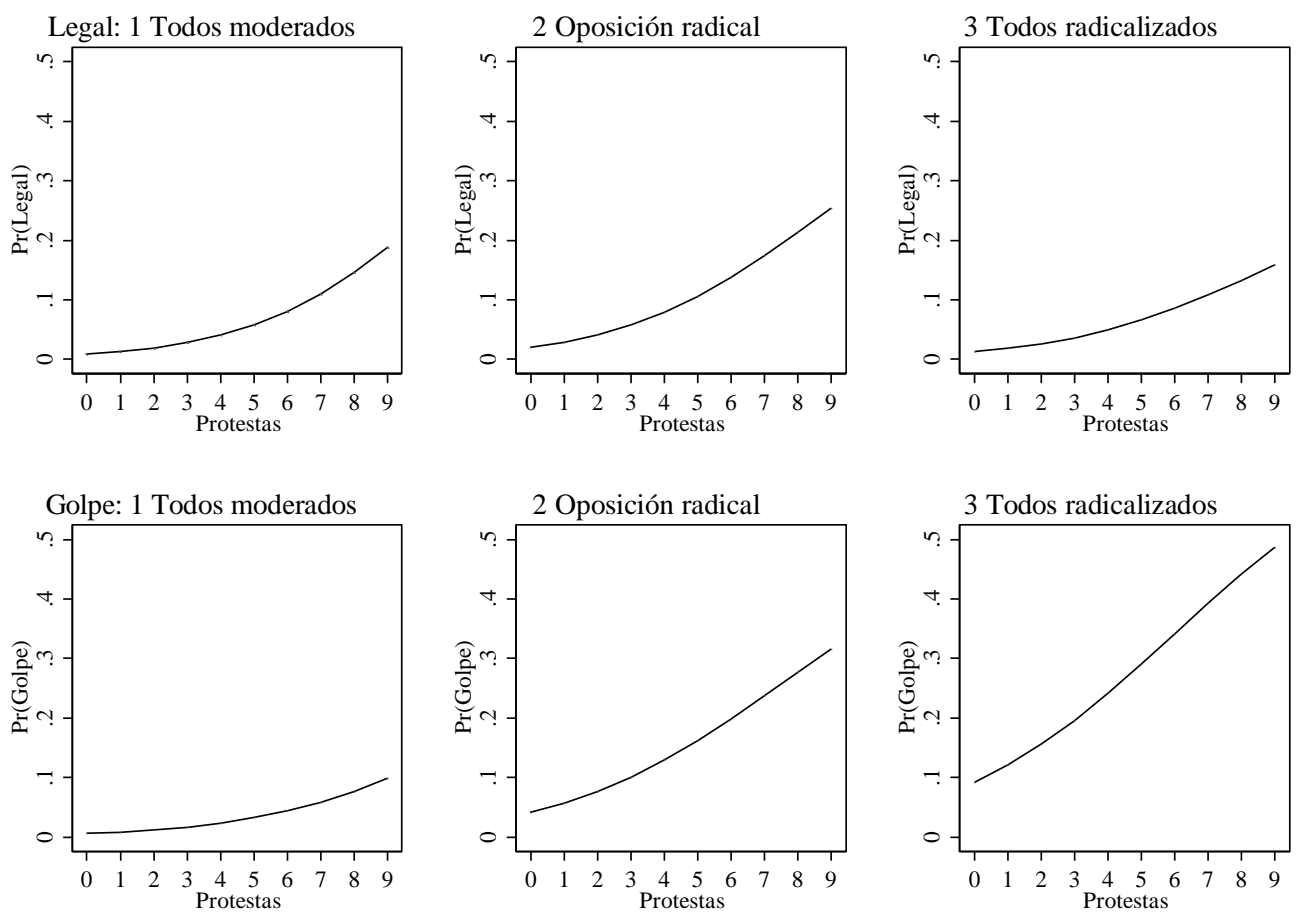

Fuente: Pérez-Liñán y Polga-Hecimovich (2015). Los valores reflejan la probabilidad media para las 729 observaciones cuando fijamos las variables de interés-manifestaciones anuales, radicalismo del gobierno y de la oposición-en diferentes valores mientras mantenemos las variables de control en sus valores históricamente observados. Los valores de radicalismo fijados para el gobierno y la oposición en cada columna son $(0,0),(0,1)$, y $(1,1)$.

El riesgo de destitución por medios civiles alcanza su valor máximo en el segundo panel de la primera fila, cuando las protestas son frecuentes, la oposición está radicalizada, y el gobierno es moderado (y por ende no bloquea los canales institucionales). Por el contrario, el mayor riesgo de golpe militar se observa en tercer panel de la segunda fila, cuando las protestas se producen en un ambiente de polarización política marcado por la radicalización del gobierno y de la oposición. En ese contexto la negociación resulta imposible, y la oposición radicalizada sólo encuentra un mecanismo para desafiar al gobierno por medio de la vía armada. 


\section{El impacto desigual del crecimiento económico}

No todos los gobiernos buscan establecer un control hegemónico sobre las instituciones, y entre aquellos que persiguen este objetivo, no todos resultan exitosos. La Figura 1 sugiere sin embargo que se ha producido un crecimiento de los gobiernos radicales en los primeros ańos del siglo XXI. Para explicar la expansión de estos proyectos políticos radicales durante los últimos 15 años, es preciso considerar el "boom" exportador mencionado en la introducción. La prosperidad del nuevo siglo permitió la adopción de políticas sociales de gran efectividad y con una amplia cobertura. Por ejemplo, en Ecuador el Bono de Desarrollo Humano alcanzó 1,5 millones de hogares, mientras que en Bolivia el bono Juancito Pinto proporcionó subsidios anuales a casi 2 millones de estudiantes en escuelas públicas (MARCO NAVARRO, 2012). Pero la amplia disponibilidad de recursos y la creciente popularidad asociada a estas políticas permitió a los presidentes de varios países desplegar lo que Kurt Weyland denominó como "legalismo discriminatorio" (WEYLAND, 2013). Esta estrategia se desplegó de forma acumulativa y secuencial: el éxito electoral condujo a un mayor control sobre las instituciones electivas y los recursos del Estado; la manipulación de los recursos del Estado a su vez condujo a un mayor control sobre las instituciones no electivas, como el poder judicial y la burocracia; y la acción (o inacción) de estas instituciones fue finalmente decisiva para silenciar a los medios críticos y socavar a la oposición política. Los líderes radicalizados emplearon así la autoridad legal del gobierno de manera discrecional para apoyar a sus aliados e intimidar a sus oponentes.

Esta lectura sugiere entonces que cuanto mayor sea la tasa de crecimiento económico en un período histórico, mayor será la capacidad de los gobiernos radicalizados para socavar la autonomía de las instituciones y debilitar a la oposición. Este proceso no es fácil de evaluar, pero para medir la evolución de la competencia política podemos emplear el índice de competencia efectiva para la Cámara Baja (o única) de la legislatura nacional. Este índice varía entre 0 y 1 , con los valores cercanos a cero indicando que el gobierno - o, en raras oportunidades, la oposición - controla todos los escańos en el congreso, y los valores cercanos a uno indicando que el tamaño de los dos bloques está equilibrado (ALTMAN y PÉREZ-LIÑÁN, 2002).

En los años ochenta y noventa la democracia latinoamericana media alcanzaba un nivel de competencia efectiva de 0,80 (ALTMAN y PÉREZ-LIÑÁN, 2002, p. 90). En un sistema bipartidista, esta puntuación reflejaría que un partido (normalmente el 
gobierno) controla el $60 \%$ de los escaños en el congreso y el otro partido, el $40 \% .^{5}$ Un valor de 0,50 , por el contrario, indicaría que el partido mayoritario controla el $75 \%$ de los escańos y la minoría, sólo el 25\%. En un sistema multipartidista, el índice refleja la brecha entre el tamaño del partido medio en la coalición de gobierno y en el bloque opositor.

Algunos países latinoamericanos mostraron una erosión considerable de la competencia durante en años recientes. Argentina redujo su puntuación de 0,89 en 1998 a sólo 0,63 hacia 2013. Bolivia la redujo de 0,94 en 2001 a 0,57 en 2013. Ecuador cayó de 0.99 en 1996 a 0.25 en 2013. En Venezuela, la medida de competencia efectiva se redujo consistentemente desde 1999 y alcanzó su punto más bajo cuando la oposición boicoteó las elecciones legislativas de 2005 (PÉREZ-LIÑÁN, 2014).

Figura 3 - Crecimiento económico y competencia efectiva, 1995-2013

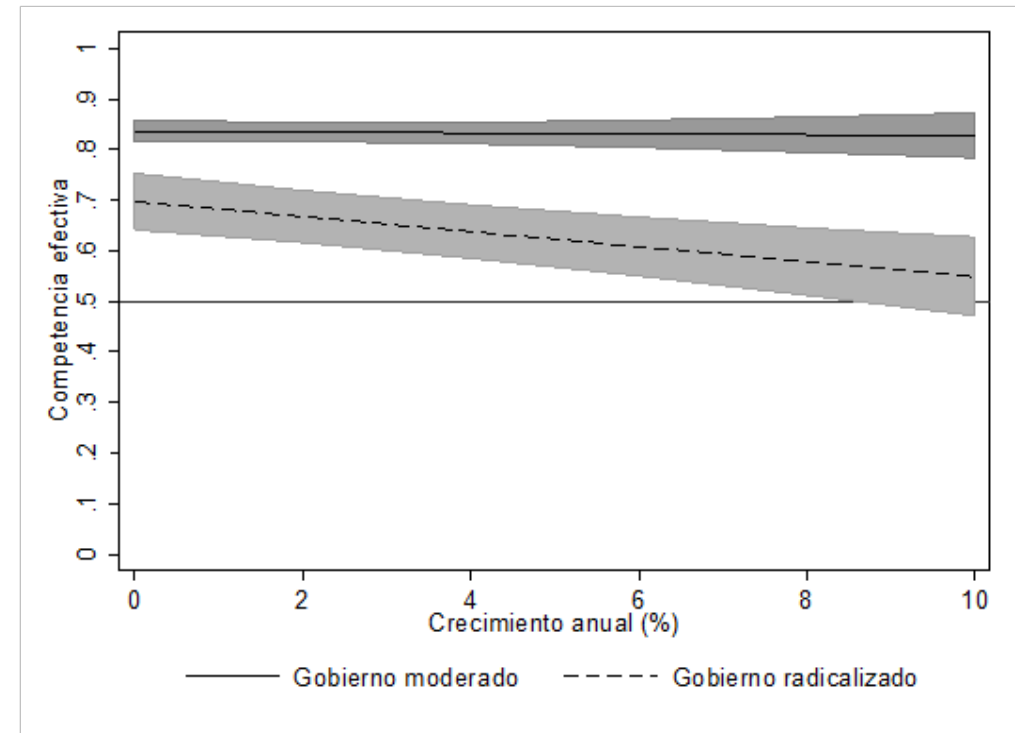

Fuente: Pérez-Liñán (2014). Los valores muestran el nivel esperado de competencia efectiva para dos grupos, gobiernos moderados (radicalización $=0$ ) y gobiernos radicalizados $(=1)$. Las bandas reflejan el intervalo de confianza al $95 \%$.

\footnotetext{
${ }^{5}$ El índice también es sensible a los desequilibrios competitivos en favor de la oposición; un valor de 0,80 también podría indicar que la oposición controla el 60\% de las curules y el gobierno, sólo el 40\%. Pero los grandes desequilibrios legislativos en favor de la oposición, incluso en los casos de gobierno dividido, son poco frecuentes (por ejemplo, Ecuador en 2005-6).
} 
¿En qué medida la prosperidad económica de los últimos 15 años permite explicar este deterioro de la competencia efectiva? La Figura 3 resume los resultados de un modelo estadístico que emplea la tasa de crecimiento económico para predecir el nivel de competencia política durante el año siguiente. El análisis incluye información para 18 países latinoamericanos entre 1995 y $2013(\mathrm{~N}=342)$ y controla por el efecto de otras posibles explicaciones. ${ }^{6}$ Entre estas variables se incluye el grado de radicalización del gobierno. El modelo emplea además un término de interacción para distinguir los efectos del crecimiento económico cuando el gobierno es moderado o es radical.

Los resultados de este análisis muestran que el crecimiento económico condujo a una reducción de la competencia política solamente en países donde el gobierno adoptó un discurso radicalizado. Esta erosión de la competencia efectiva no se produjo en países que adoptaron políticas sociales exitosas, como Brasil y Uruguay, en donde la oposición mantuvo un rol importante y en donde los presidentes articularon coaliciones legislativas con otros partidos o con diversas fracciones dentro del partido gobernante. La alternativa de un presidencialismo pluralista, entonces, permaneció abierta en el siglo XXI como una opción viable frente a los proyectos de transformación social más intolerantes (LANZARO, 2013; PEREIRA y MELO, 2012).

\section{Consecuencias de la erosión institucional para la supervivencia del régimen}

Un trabajo sobre este tema muestra que el mecanismo central que produce esta erosión de la competitividad es la restricción de la deliberación pública por medio del hostigamiento de la oposición y el control abierto o sutil de los medios de comunicación (ALTMAN y PÉREZ-LIÑÁN, 2015). La consecuencia inmediata del proyecto hegemónico es entonces la transformación del régimen democrático en una semidemocracia, un régimen competitivo en el que existen violaciones parciales al respeto por las elecciones limpias o las libertades civiles.

Como mencioné en la sección sobre inestabilidad presidencial, esta erosión de las condiciones institucionales acorrala a la oposición e incentiva una estrategia de desestabilización del régimen. En un estudio en curso con Scott Mainwaring documentamos que este mecanismo se despliega a través de una secuencia causal que involucra dos eslabones. En un primer momento, la radicalización de los actores sociales promueve la conformación de una semi-democracia, o bien porque las conductas de

\footnotetext{
${ }^{6}$ Los controles incluyen el nivel de ingreso per cápita, un índice de transparencia gubernamental (HOLLYER, ROSENDORFF y VREELAND, 2014), variables dicotómicas para identificar presidentes interinos y gobiernos de coalición, y el grado de radicalismo de la oposición.
} 
estos actores erosionan una democracia ya establecida, o bien porque impiden que un régimen en transición desarrolle respeto pleno por los principios democráticos. En un segundo momento, la existencia de una situación semi-democrática torna el régimen mucho más frágil $y$ promueve una salida autoritaria (PÉREZ-LIÑÁN y MAINWARING, 2015b).

Dos aspectos de esta secuencia merecen especial atención. En primer lugar, no sólo la presencia de un gobierno radicalizado, sino también el surgimiento de una oposición radicalizada, tienden a crear una situación semi-democrática. Los gobiernos radicales están dispuestos a socavar los frenos y contrapesos democráticos con el fin de alcanzar sus objetivos de política pública. Las fuerzas de oposición tienen menor capacidad para socavar unilateralmente las instituciones a nivel nacional, pero pueden hacerlo en partes del territorio cuando controlan la política sub-nacional. Además, las oposiciones radicalizadas a menudo inspiran temor en el establishment político, por lo que los gobiernos tienden a resistir una mayor democratización para prevenir que los opositores ganen espacio, y eventualmente llegan a restringir las libertades civiles para detener su ascenso.

Nuestro análisis de este problema utiliza datos de 20 países de América Latina entre 1944 y 2010. Las unidades de análisis son regímenes competitivos (democráticos o semi-democráticos) observados de manera anual, conformando un total de 753 observaciones. Incluso controlando por numerosas explicaciones alternativas - como el ingreso nacional per cápita, la tasa de crecimiento económico, las dependencia de exportaciones de petróleo y minerales, el tamaño de la fuerza de trabajo industrial, la difusión regional de la democracia, el compromiso normativo de las élites con el sistema y la edad del régimen - la evidencia muestra que en los países con élites radicalizadas el régimen competitivo es mucho más propenso a ser una semi-democracia que una democracia plena. Los resultados de un modelo probit sugieren que, si asumimos que todas las demás variables permanecen en sus valores históricos, el régimen competitivo típico será apenas una semi-democracia con una probabilidad del $25 \%$ cuando todos los actores son moderados, del $43 \%$ cuando el gobierno es radical y la oposición es moderada, y del $66 \%$ cuando los gobernantes y sus oponentes son radicales. Ya sea que estén en el gobierno o en la oposición, los actores radicales bloquean el surgimiento de democracias plenas o producen la erosión de ya existentes, deslizando el régimen hacia la semi-democracia.

El segundo aspecto que merece atención es que la conformación de un sistema semi-democrático reduce la capacidad de supervivencia del régimen más allá del efecto desestabilizador producido por los actores radicales. Diversos estudios estadísticos han 
demostrado que los regímenes semi-democráticos son mucho más vulnerables que las democracias plenas: Epstein et al. (2006) mostraron que las democracias parciales son más volátiles que las democracias puras o los regímenes autoritarios; Goldstone et al. (2010) documentaron que las democracias parciales tienen más probabilidades de sufrir transformaciones adversas que las autocracias o democracias plenas; y Knutsen y Nygård (2015, p. 657) encontraron que "los regímenes que combinan características democráticas y autocráticas tienen menores expectativas de vida".

Cabe sospechar que esta fragilidad de los regímenes semi-democráticos se deba simplemente a que existen condiciones causales no observadas (desconocidas o no mensurables) que debilitan los regímenes democráticos, haciendo que éstos se tornen semi-democracias primero y sufran un quiebre autoritario después. De ser este el caso, resultaría trivial afirmar que las situaciones semi-democráticas "generan" inestabilidad, dado que su existencia misma sería resultado de las mismas fuerzas que en última instancia generan el colapso del régimen. Para descartar esta posibilidad estimamos un modelo de selección que asume que el "tratamiento" (en este caso, la instauración de una semi-democracia) no se distribuye de manera aleatoria entre los regímenes observados (HECKMAN, 1978; MADDALA, 1983).

Los resultados de este análisis confirman que las semi-democracias - aun aceptando la posibilidad de que factores no observados afecten su distribución - son una fuente real de inestabilidad. Mientras que el riesgo de golpe estimado anualmente se aproxima a cero para una democracia plena, el riesgo anual estimado para una semidemocracia varía entre el 5\% y el 11\%, dependiendo de la técnica estadística empleada. Esto sugiere una esperanza media de vida para las semi-democracias de entre una y dos décadas. En estos modelos, el efecto directo del radicalismo sobre la probabilidad de quiebre democrático se torna estadísticamente insignificante, indicando que el radicalismo tiende a desestabilizar la democracia de manera indirecta: al promover la erosión de las garantías institucionales, dispara una escalada de intolerancia y de conflicto político que debilita al régimen (PÉREZ-LIÑÁN y MAINWARING, 2015b).

Este resultado lleva a preguntarse qué características de la semi-democracia son las que producen mayor inestabilidad. Para explorar esta cuestión analizamos la relación entre la calidad de la democracia y la durabilidad del régimen, evaluando el efecto de cuatro dimensiones de calidad democrática: los niveles de competencia efectiva, la participación política, la fortaleza del estado de derecho, y la rendición de cuentas horizontal del ejecutivo a otras instituciones (PÉREZ-LIÑÁN y SMITH, 2015). El análisis estadístico de 18 países latinoamericanos entre 1945 y 2010 (n = 
707) muestra que la ausencia de rendición de cuentas horizontal - medida a través del índice de restricciones al ejecutivo del proyecto Polity IV - y un pobre desempeño económico son los principales factores que desestabilizan el régimen. La erosión de otras dimensiones de calidad democrática no representa una causa directa de inestabilidad, pero pone en marcha el proceso de deterioro institucional. Un sistema de ecuaciones simultáneas muestra que una reducción en las tasas de participación electoral o en los niveles de competencia efectiva (medida con el índice descripto en la sección anterior) conduce a un deterioro de la rendición de cuentas del ejecutivo, lo que a su vez aumenta el riesgo de autoritarismo. Estos hallazgos refuerzan así las conclusiones presentadas en las secciones previas, destacando que la reducción de la competencia política es parte del proceso de erosión institucional, y que la capacidad de los presidentes para cerrar las vías institucionales de control constituye una de las principales razones que impulsan a la oposición a buscar una vía inconstitucional para derrocar al gobierno.

\section{Preferencias, agencia y responsabilidad politica}

La Figura 4 integra los hallazgos de los diferentes estudios resumidos a lo largo de este ensayo. La evidencia histórica indica que (1) la radicalización de los actores en el gobierno promueve una creciente erosión institucional, restringiendo la deliberación pública, reduciendo la competencia política efectiva, y en última instancia estableciendo una semi-democracia; (2) esta erosión institucional es mucho más pronunciada cuando los gobiernos radicalizados tienen acceso a los recursos generados por una elevada tasa de crecimiento económico, como en el período 20032013; (3) la erosión institucional genera una dinámica de polarización política que incentiva a la oposición a buscar una alternativa militar para derrotar al gobierno, y a su vez incentiva al gobierno a aumentar la represión de la oposición desleal, facilitando en última instancia el quiebre del régimen competitivo. Por su parte, la radicalización de la oposición la induce a buscar (4) formas institucionales (como el juicio político) o civiles (como la protesta social) para destituir al presidente por medios legales, pero también, dependiendo del contexto histórico, deja abierta la posibilidad de que los opositores (5) busquen desestabilizar al gobierno por medios para-constitucionales. Esta estrategia produce también erosión institucional y conduce al quiebre del régimen, o bien porque una insurrección armada derrota al gobierno, o porque el gobierno aumenta los niveles de represión para subsistir. 
Figura 4 - Consecuencias de la radicalización para la (in)estabilidad democrática Radicalización

Inestabilidad

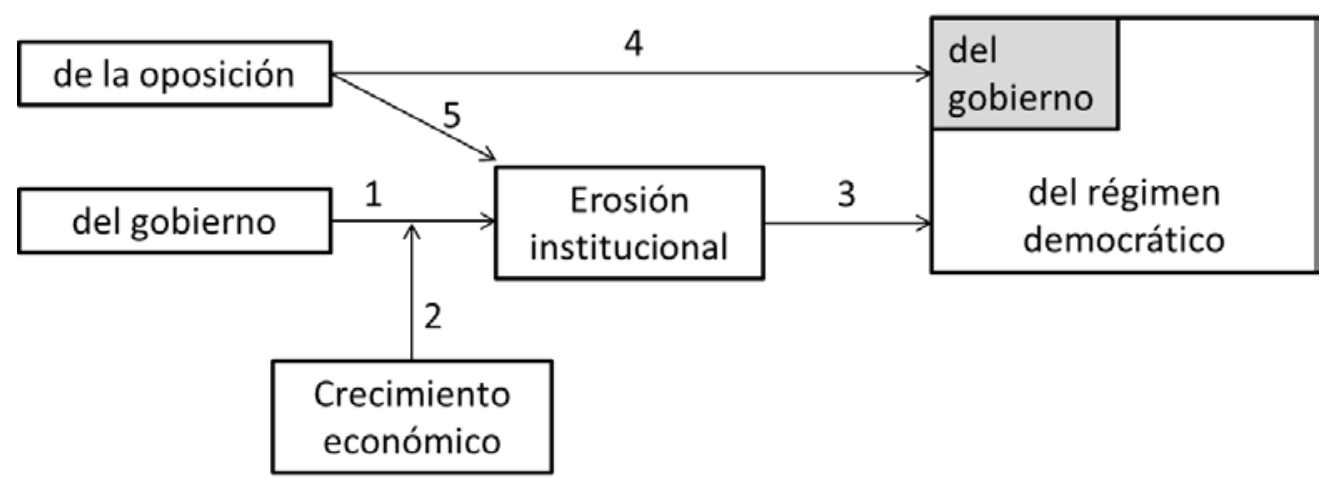

Fuente: Elaboración propia.

Tomados en conjunto, estos resultados sugieren dos importantes conclusiones. En primer lugar, y retornando a la primera pregunta que motiva la introducción de este ensayo, la democracia latinoamericana no parece enfrentar un peligro inminente si aceptamos como válidos los indicadores de radicalización presentados en la Figura 1. A pesar de la tendencia creciente a la radicalización de algunos gobiernos a comienzos del siglo XXI, los niveles observados permanecen por debajo de la media histórica. La media regional, sin embargo, oculta una variación sustancial entre los diferentes países. La dinámica de polarización y potencial inestabilidad descripta en las secciones anteriores constituye un riesgo real para la próxima década en países con altos grados de polarización como Venezuela y, en menor medida, Ecuador.

En segundo lugar, el análisis refuerza las conclusiones de un estudio reciente desarrollado por Rut Diamint y Laura Tedesco $(2015$, p. 2), quienes argumentan que "el liderazgo importa en América Latina posiblemente más que en ninguna otra región”. Este libro sostiene que los actores que mejoran la calidad de la democracia son líderes que buscan el fortalecimiento de las instituciones, construyen consensos y evitan la polarización, aceptan las restricciones impuestas por la ley, respetan los derechos civiles, y aceptan los límites a su permanencia en el poder. Por el contrario, los líderes que buscan usurpar el poder democrático manipulan las normas, adoptan posturas intransigentes que incentivan la polarización y buscan prolongar su permanencia en el poder más allá de las expectativas constitucionales (DIAMINT y TEDESCO, 2015). 
Las autoras conceptualizan estos tipos ideales como polos de un continuo, y reconocen que los líderes están restringidos por la naturaleza del sistema de partidos. También es verdad que los líderes operan dentro de un contexto siempre definido por la historia política de cada país. Sin embargo, un análisis de los legados históricos que afectaron la democratización latinoamericana en el período posterior a 1978 sugiere que las estrategias adoptadas por las élites políticas en el pasado - preservadas por el sistema de partidos y el poder judicial - más que la cultura política de masas en cada país, determinan los parámetros para la evolución democrática en el presente (PÉREZ-LIÑÁN y MAINWARING, 2013).

Esta interpretación nos obliga a considerar la segunda cuestión que abre este trabajo. Afirmar que los actores políticos tienen responsabilidad en la construcción de la democracia resulta un cliché, pero la literatura más influyente en ciencia política a pesar de raras excepciones como la obra de Diamint y Tedesco (2015) - no es particularmente consistente con esta afirmación.

En el siglo pasado, la "revolución conductista" transformó el estudio de la política en una empresa científica. También creó un consenso académico por el cual el comportamiento político, definido en términos generales, se convirtió en explanandum (la variable dependiente) y rara vez en explanans (una variable independiente). Este enfoque desafía la intuición de ciudadanos y políticos, para quienes las decisiones de los líderes (lideresas) son la principal causa de los resultados observables en el mundo político. La ciencia política, por su parte, está naturalmente inclinada a explicar estas decisiones como producto de fuerzas estructurales, de limitaciones institucionales, o de condiciones de equilibrio estratégico que determinan el comportamiento de los actores. Los argumentos que invocan "agencia" a menudo muestran una preocupación por la contingencia histórica que recela cualquier ambición de proporcionar explicaciones generales para una clase de acontecimientos.

En un momento en que un número creciente de voces exigen una nueva ciencia política capaz de trascender el aislamiento académico para comprometerse con el debate público (ISAAC, 2015), la teorización de la responsabilidad política resulta de especial relevancia. Es preciso entonces restablecer una perspectiva analítica que nos permita reconocer la autonomía moral del liderazgo político y que al mismo tiempo inspire teorías científicas sobre la democracia que puedan verse sujetas a verificación empírica. 


\section{Aníbal Pérez-Liñán é Doutor em Ciência Política pela} Univesidade de Notre Dame. É Professor do Departamento de Ciência Politica da Universidade de Pittsburgh. E-mail: anibal.perez.linan@gmail.com.

\section{Referências}

ALTMAN, David; PÉREZ-LIŃÁN, Aníbal. Assessing the Quality of Democracy: Freedom, Competitiveness, and Participation in Eighteen Latin American Countries. Democratization, v. 9. n. 2, p. 85-100, 2002.

ALTMAN, David; PÉREZ-LIŃÁN, Aníbal. Can Sustained Growth Hinder Democracy? The Politics of Intolerant Progress in Latin America. Red para el Estudio de la Economía Politica de América Latina - REPAL, Montevideo, 7-8 jul. 2015.

BERMEO, Nancy. Ordinary People in Extraordinary Times. The Citizenry and the Breakdown of Democracy. Princeton: Princeton University Press, 2003.

DAHL, Robert A. Polyarchy: Participation and Opposition. New Haven: Yale University Press, 1971.

DIAMINT, Rut; TEDESCO, Laura. Latin America's Leaders. London: Zed Books, 2015.

EPSTEIN, David L. et al. Democratic Transitions. American Journal of Political Science, v. 50, n. 3, p. 551-569, 2006.

GOLDSTONE, Jack A. et al. A Global Model for Forecasting Political Instability. American Journal of Political Science, v. 54, n. 1, p. 190-208, 2010.

HECKMAN, James J. Dummy Endogenous Variables in a Simultaneous Equation System. Econometrica, v. 46, n. 4, p. 931-959, 1978.

HOCHSTETLER, Kathtryn. Rethinking Presidentialism: Challenges and Presidential Falls in South America. Comparative Politics, v. 38, n. 4, p. 401-418, 2006.

HOLLYER, James R.; ROSENDORFF, B. Peter; VREELAND, James Raymond. Measuring Transparency. Political Analysis v. 22, n. 4, p. 413-434, 2014.

ISAAC, Jeffrey C. For a More Public Political Science. Perspectives on Politics, v. 13, n. 2, p. 269-283, 2015.

KARL, Terry L. Petroleum and Political Pacts: The Transition to Democracy in Venezuela. Latin American Research Review, v. 22, n. 1, p. 63-94, 1987.

KNUTSEN, Carl Henrik; NYGÅRD, Håvard Mokleiv. Institutional Characteristics and Regime Survival: Why Are Semi-Democracies Less Durable Than Autocracies and Democracies? American Journal of Political Science, v. 59, n. 3, p. 656-670, 2015.

LANZARO, Jorge. Presidencialismo y parlamentarismo: América Latina y Europa Meridional. Madrid: Centro de Estudios Políticos y Constitucionales, 2013. 
LEVINE, Daniel H. Conflict and Political Change in Venezuela. Princeton: Princeton University Press, 1973.

LINZ, Juan J. The Breakdown of Democratic Regimes: Crisis, Breakdown, and Reequilibration. Baltimore: The Johns Hopkins University Press, 1978.

MADDALA, G. S. Limited-Dependent and Qualitative Variables in Econometrics. Cambridge: Cambridge University Press, 1983.

MAINWARING, Scott; BRINKS, Daniel; PÉREZ-LIÑÁN, Aníbal. Classifying Political Regimes in Latin America, 1945-2004. In: MUNCK, Gerardo (Comp.). Regimes and Democracy in Latin America. Theories and Methods. Oxford: Oxford University Press, 2007.

MAINWARING, Scott; PÉREZ-LIÑÁN, Aníbal. Democracies and Dictatorships in Latin America: Emergence, Survival, and Fall. Cambridge: Cambridge University Press, 2013.

MARCO NAVARRO, Flavia. El Bono Juancito Pinto del Estado Plurinacional de Bolivia: Programas de transferencias monetarias e infancia. Santiago: Comisión Económica para América Latina y el Caribe, 2012.

MAZZUCA, Sebastián L. The Rise of Rentier Populism. Journal of Democracy, v. 24, n. 2, p. 108122, 2013.

PEREIRA, Carlos; MELO, Marcus Andre. The Surprising Success of Multiparty Presidentialism. Journal of Democracy, v. 23, n. 3, p. 156-170, 2012.

PÉREZ-LIÑÁN, Aníbal. Pluralismo y competencia electoral en el Siglo XXI. Congreso Internacional de Estudios Electorales, 2., Lima, 27-29 nov. 2014.

PÉREZ-LIÑÁN, Aníbal; MAINWARING, Scott. Democracies and Dictatorships in Latin America: Emergence, Survival, and Fall. Cambridge: Cambridge University Press, 2014.

PÉREZ-LIÑÁN, Aníbal; MAINWARING, Scott. La supervivencia de la democracia en América Latina (1945-2005). América Latina Hoy, n. 68, p. 139-168, 2015a.

PÉREZ-LIÑÁN, Aníbal; MAINWARING, Scott. Radicalism and Democratic Backsliding in Latin America. Shambaugh Workshop on Democratization and Backsliding, Iowa, USA, 23-26 abr. 2015 b.

PÉREZ-LIÑÁN, Aníbal; POLGA-HECIMOVICH, John. Coups, Impeachments, and the Stability of Latin American Democracy. American Political Science Association, San Francisco, 3-6 Sep. 2015.

PÉREZ-LIÑÁN, Aníbal; SMITH, Noah. Democratic Quality and Democratic Survival. Ponencia presentada a The Quality of Democracy: The Challenges of a New Research Agenda, Université Libre de Bruxelles and ESPOL, Université Catholique de Lille, 5-7 de marzo, 2015.

ROS, Jaime. Latin America's Trade and Growth Patterns, the China Factor, and Prebisch's Nightmare. Journal of Globalization and Development, v. 3, n. 2, p. 1-16, 2013.

URCUYO, Constantino. La Presencia China en América Latina: Dragón comerciante, consumista y prudente. In: DABÈNE, Olivier (Comp). Political Outlook 2013 de América Latina. Paris: Observatoire Politique de l'Amerique Latine et des Caraibes, 2013. p. 9-22.

WEYLAND, Kurt. The Threat from the Populist Left. Journal of Democracy, v. 24, n. 3, p. 18-32, 2013. Aprovado em 16 de março de 2016. 